\title{
Biomarker radiocarbon evidence of terrestrial organic carbon aging during transport within in Pearl River estuary
}

\author{
P.Hou ${ }^{1,2,3}$, T.I.EGLINTON ${ }^{2 *}$, N.HAGHIPOUR ${ }^{2}$, \\ D.B.MONTLUÇON ${ }^{2}$, M. ZHAO ${ }^{1,3 *}$
}

${ }^{1}$ Frontiers Science Center for Deep Ocean Multispheres and Earth System, and Key Laboratory of Marine Chemistry Theory and Technology, Ministry of Education, Ocean University of China, Qingdao 266100, China

(*correspondence: maxzhao@ouc.edu.cn)

${ }^{2}$ Geological Institute, Department of Earth Sciences, ETH Zürich, 8092 Zürich, Switzerland (*correspondence: timothy.eglinton@erdw.ethz.ch)

${ }^{3}$ Laboratory for Marine Ecology and Environmental Science, Qingdao National Laboratory for Marine Science and Technology, Qingdao 266237, China

Large river estuaries are highly dynamic, with sediment transport and depositional processes occurring over a broad range of spatial and temporal scales. Understanding the fate of terrestrial organic carbon $\left(\mathrm{OC}_{\text {terr }}\right)$ in large river estuaries is important for evaluating carbon cycle processes in these dynamic land-ocean environments. In this study, we employed compound-specific radiocarbon analysis on both suspended particulate matter (SPM) samples and surface sediments from the upper and the lower Pearl River estuary to examine the spatiotemporal variation of $\mathrm{OC}_{\text {terr. }}$ Our results revealed ${ }^{14} \mathrm{C}$ aging of long-chain fatty acids (LCFAs, $\mathrm{C}_{24}-\mathrm{C}_{32}$ ) along the $60 \mathrm{~km}$ dispersal pathways of fluvially derived materials. The ${ }^{14} \mathrm{C}$ ages of LCFAs for SPM samples increased by about $540-1650 \mathrm{yr}$, while the ${ }^{14} \mathrm{C}$ ages of LCFAs for surface sediments increased by about $2160-4220$ yr. LCFA ages in sediments were always older than those in the corresponding SPM at the same sites. In addition, the discrepancy of LCFAs age between SPM and corresponding sediment increased along the salinity gradient. This transportrelated aging of $\mathrm{OC}_{\text {terr }}$ in the Pearl River estuary is likely because of 1) selective degradation of more labile OC by the cyclic deposition-resuspension processes; 2) protracted lateral transport time caused by daily tidal activities. 